\title{
Yabancıların Türkçe Öğrenme Kaygıları Ölçeği: Güvenirlik ve Geçerlik Çalışması
}

\author{
Oğuzhan Sevim*,
}

Makale Geliş Tarihi: 05.11.2019

Makale Kabul Tarihi:12.12.2019

DOI: $10.35675 /$ befdergi. 642780

$\ddot{O} z$

Bu araştırmanın amacı yabancıların Türkçe öğrenme kaygllarını ölçmek amacıyla güvenilir ve geçerli bir ölçek geliştirmektir. Bu amaç doğrultusunda önce nitel, sonra nicel verilerin toplanması ve analizi hedeflendiğinden bu çalışma, karma yöntem araştırma desenlerinden keşfedici desenin ilkelerine uygun olarak gerçekleştirilmiştir. Araştırmanın amacı doğrultusunda 2018-2019 öğretim yllında Nişantaşı, Atatürk Üniversitesi ve Harran üniversitelerinde ögrenim gören en az A2 düzeyinde Türkçe bilen 325 yabancı uyruklu ögrenciye 33 maddeden oluşan taslak ölçek uygulanmıştır. Ölçeğin yap geçerliği için açıklayıcı faktör analizi uygulanmış ve binişik faktör yüklerinden dolayı 6 madde elenmiştir. Dört faktörlü bir yapıya sahip olduğu anlaşılan ölçeğe doğrulayıcı faktör analizi yapılmış ve t değerlerinin 1,96'dan düşük, hata varyanslarının ise yüksek olmasından dolayı 5 madde elenmiş, tekrarlanan analizde kurulan modelin uyum değerlerinin iyi olduğu anlaşılmıştır. Ölçeğin güvenirliği için Cronbach alfa katsayısına bakılmış ve 0,90 olarak bulunan değerin yüksek derecede bir güvenirliği ifade ettiği belirlenmişstir. Ölçek maddelerinin ayırt ediciliklerinin hesaplanması için ise \%27 alt ve üst grupların $t$ değerlerine bakılmış, ölçek maddelerinin ayırt edici oldukları tespit edilmiştir. Araştırmanın sonunda güvenirlik ve geçerlik çalışmaları yapılmış 22 maddeden oluşan dört faktörlü bir yapıya sahip ölçek elde edilmiştir.

Anahtar Kelimeler: Ölçek geliştirme, Türkçe öğrenme kaygısı, yabancılara Türkçe ögretimi.

\section{Turkish Learning Anxiety Scale of Foreigners: A Reliability and Validity Study}

\begin{abstract}
The aim of this study is to develop a reliable and valid scale in order to measure the Turkish anxiety of foreigners. For this purpose, firstly qualitative and then quantitative data collection and analysis is aimed, this study was carried out in accordance with the principles of exploratory design from mixed method research designs.In line with the aim of the research, a draft scale consisting of 33 items was applied to 325 foreign students who know Turkish at least A2 level in Nişantaşl, Atatürk University and Harran Universities in 20182019 academic year. For the construct validity of the scale, explanatory factor analysis was applied and 6 items were eliminated due to overlapping factor loads. Confirmatory factor
\end{abstract}

* Atatürk Üniversitesi, Kazım Karabekir Eğitim Fakültesi, Türkçe ve Sosyal Bilimler Eğitimi Bölümü, Erzurum, Türkiye, o.sevim@atauni.edu.tr, ORCID: 0000-0001-7533-4724

Kaynak Gösterme: Sevim, O. (2019). Yabancıların Türkçe öğrenme kaygıları ölçeği: Güvenirlik ve geçerlik çalışması. Bayburt Eğitim Fakültesi Dergisi, 14(28), 253-274. https://doi.org/ $10.35675 /$ befdergi. 642780 
analysis was performed on the scale which was found to have a four-factor structure, and 5 items were eliminated because t values were less than 1.96 and error variances were high, and the fit values of the model established in repeated analysis were found to be good. For the reliability of the scale, Cronbach's alpha coefficient was examined and the value of 0.90 was found that indicates a high degree of reliability. In order to calculate the distinctiveness of the scale items, $t$ values of $27 \%$ lower and upper groups were examined and it was determined that the scale items were distinctive. At the end of the study, reliability and validity studies were conducted and a four-factor scale consisting of 22 items was reached.

Keywords: Scale development, Turkish learning anxiety, Turkish teaching to foreigners.

\section{Giriş}

İçinde bulunduğumuz yüzyıl bilimsel ve teknolojik gelişmelerin hızlı bir şekilde sürdüğü, insan yaşamının ise bu gelişmelerden her zamankinden çok daha fazla etkilendiği bir zaman dilimidir. Yeni iletişim araçlarının gelişmesi, insanlar arasındaki mesafeleri ortadan kaldırmış, küresel bir yaşam modelini insanların hizmetine sunmuştur. Bu yeni yaşam modelinde ise yabancı dil öğrenme oldukça önemli bir konu hâline gelmiştir. İnsanlar merak ettikleri coğrafyaları, ülkeleri, toplumları ve kültürleri tanımak için o coğrafyalarda yaygın olarak konuşulan dilleri öğrenmeye yönelmişlerdir.

Yabancı bir dil öğrenme; bireysel farklılık, beceri, zekâ tipleri, motivasyon, kendini hazır hissetme, tutum gibi pek çok faktörün etkisinde gelişen bir süreçtir (Senemoğlu, 2004; Schunk, 2008; Yeşilyaprak, 2011). Yabancı dil öğrenme sürecinde bireylerin sıklıkla yaşadıkları duygulardan biri de kaygıdır. Kaygı düzeyi dil öğrenme sürecini olumlu ya da olumsuz etkileme gücüne sahip bir duygudur (MacIntyre ve Gardner, 1994; Ganschow ve Sparks, 1996; Aydın, 1999). Bu sebeple yabancı dil öğretiminde kişilerin o dili öğrenmeye ilişkin yaşadıkları kaygı düzeyi, öğrenme sürecinin belirleyicilerinden biri olarak görülebilir (Horwitz ve Young, 1991; MacIntyre ve Gardner, 1994; Cheng, Horwitz ve Shallert, 1999; Aydın ve Zengin, 2008; Batumlu, 2006).

Farklı olaylar karşısında verilen doğal tepkilerden biri olan kaygı, bireyin hem biliş hem de duygu durumunu etkileyen, işlerin iyi ya da kötü gitmesine neden olan, sebepleri kişi tarafından da tam olarak bilinmeyen histir. İnsan kaygı duymaya başladığında başarısızlık duygusu, endişe, korku, tedirginlik, acizlik gibi heyecanlardan birini ya da birden çoğunu aynı anda duymaya başlar (Ünlü, 2001). Bahsi geçen bu duyguları her insan yaşar fakat bu duyguları nasıl ve niçin hissettiğini bilmez. Bir şeyler yolunda gitmediğinde ortaya çıkan kaygı bireyin varlığından hoşlanmadığı bir duygudur (Üldaş, 2005). Kaygı her ne kadar varlığından rahatsız olunan bir duygu olsa da kişide az miktarda bulunması, onun olası tehlikelere ya da olumsuzluklara hazırlıklı olmasına da yardımcı olur (Akgün, Gönen ve Aydın, 2007; Tekindal, 2009). 
Bireylerin yeni bir dil öğrenmesi fizyolojik, sosyolojik ve psikolojik bir süreç içerisinde gerçekleşmektedir. Kişilerin kaygı hâli dil öğrenme sürecinin önündeki en büyük engellerden biridir. Yabancı dil öğrenenlerin duygu ve düşüncelerini hedef dilde başarılı bir şekilde paylaşamayacağı düşüncesiyle yaşadıkları kaygı hâli, öğrenmelerini doğrudan etkilemektedir (Aktaş, 2018). Horwitz, Horwitz ve Cope (1986) yabancı dil kaygısının yabancı dil öğrenme sürecine özgü bir kavram olduğunu ilk kez dile getirerek yabancı dil öğrenme sınıflarının yüksek düzeyli kayg1 ortamları olduğunu öne sürmüşlerdir. Anadilinde kendini ifade etme konusunda oldukça başarılı olan bireylerin yabancı dil öğrenme söz konusu olduğunda, yaşanması muhtemel iletişim başarısızlıklarından dolayı benlik algılarının baskılandığı, korku, heyecan, endişe ve panik durumlarının ortaya çıktığı, kendilerini ifade etmekte zorlandıkları görülmüştür (Cheng, Horwitz ve Shallert, 1999; Horwitz, Horwitz ve Cope, 1986).

Alanyazın incelendiğinde Türkiye'de yabancı dil öğrenme kaygısı üzerine yapılan çalışmalarında araştırmacıların genelde İngilizce öğrenme kaygısı üzerinde yoğunlaştığı görülmektedir. Bu çalışmalarda yabancı dil öğrenenlerin başarıları; cinsiyet, yaş, zorunlu/isteyerek öğrenme durumu, evde ikinci dil kullanma durumu, anne eğitim düzeyi, baba eğitim düzeyi (Batumlu ve Erden, 2007; Öner, 2008; Pan, 2014) gibi değişkenler açısından incelenmiştir. Araştırmalarda, kaygının başarıyı düşürdüğü (Aydın, 2016; Batumlu ve Erden, 2007; Gülözer, 2010; Öner, 2008), yabancı dil öğrenme kaygı düzeyinin yüksek olduğu (Pan, 2014), zorunlu olarak İngilizce öğrenenlerin kaygılarının seçmeli olarak öğrenenlerden yüksek olduğu (Genç, 2009), yaş değişkeni açısından (Genç, 2009) ve cinsiyet değişkeni açısından yabancı dil öğrenme kaygısında anlamlı bir farklılık görülmediği (Genç, 2009; Öner, 2008) sonuçlarına ulaşılmıştır. Lise öğrencilerinde yabancı dil kaygısının incelendiği bir çalışmada (Aydın, 2016) ise öğrencilerde utangaçlıkla yabancı dil kaygısı arasında ve yabancı dile duyulan ilgiyle yabancı dil kaygısı arasında pozitif yönlü bir ilişkinin olduğu, motivasyonla yabancı dil kaygısı arasında ise negatif yönlü bir ilişkinin olduğu sonuçlarına ulaşılmıştır.

Türkçe öğrenen yabancıların kaygılarını belirlemeye yönelik yapılan çalışmalarda; yaş, cinsiyet, devam ettikleri kur düzeyi, meslek, öğrencilerin ana dilleri ve geldikleri ülkeler, bilinen diğer dillerin sayısı, Türkçe öğrenme ve Türkiye'ye gelme sebepleri, Türkiye'de geçirilen süre (Aktaş, 2018; Boylu ve Çangal, 2015; Erdil, 2016; Özdemir, 2013; Tunçel, 2014; Y1lmaz, 2018;) gibi değişkenler incelenmiştir. Yapılan araştırmalarda; yaş değişkeninin kaygı düzeyinde anlamlı bir farklılığa neden olmadığı (Aktaş, 2018; Boylu ve Çangal, 2015; Erdil, 2016; Melanlığlu ve Demir, 2013; Şen ve Boylu, 2015; Yılmaz, 2018), öğrencilerin geldikleri ülkeler ve konuştukları diller incelendiğinde de bu değişkenlerin kaygı düzeyinde anlamlı bir fark oluşturmadığı (Erdil, 2016; Özdemir, 2013; Şen ve Boylu, 2015), ana dili dışında bilinen dil sayısının, Türkiye'ye gelme ve Türkçe öğrenme nedeninin de kaygı düzeyinde anlamlı bir farka yol açmadığı sonuçlarına ulaşılmıştır (Erdil, 2016; Özdemir, 2013). Cinsiyet değişkeni açısından kaygı 
düzeyinde anlamlı bir farklılığın olmadığını belirleyen araştırmalar olduğu gibi (Aktaş, 2018; Boylu ve Çangal, 2015; Erdil,2016; Özdemir, 2013; Sevim, 2014; Tunçel, 2014; Yılmaz, 2018) kız öğrencilerin erkek öğrencilerden daha kaygilı olduğunu belirleyen (Karçiç ve Çetin, 2015) araştırma sonucu da bulunmaktadır. Alanyazına bakıldığında, yapılan çalışmalar içerisinde yabancı öğrencilerin kaygı düzeylerinin yüksek düzeyde olduğunu ifade eden araştırmanın (İşcan, 2016) yanı sıra kaygı düzeylerinin orta seviyede olduğunu tespit eden birden fazla araştırmanın (Erdil, 2016; Yılmaz, 2018; Yoğurtçu ve Yoğurtçu, 2013) yer aldığı görülmektedir. Bir çalışmada ise kaygı düzeyi orta seviyede olan öğrencilerin ileri ve düşük seviyede kaygılı olanlara kıyasla daha başarılı olduğu ve kaygı düzeyi arttıkça motivasyon düzeyinin azaldığı (Tunçel, 2014) tespit edilmiştir. Yine başka bir çalışmada yabancı öğrencilerdeki kaygı hâlinin giderilmesinde öğretmenin öğretim metotlarını verimli kullanmasının etkili olduğu sonucuna ulaşılmıştır (Aktaş, 2018).

Alanyazına genel olarak bakıldığında Türkiye'de yabancı dil öğrenme kaygısı konusundaki çalışmaların genellikle İngilizce öğrenme kaygısı üzerinde yoğunlaştığı, geliştirilen ölçeklerin yabancı bir dilden Türkçeye uyarlama şeklinde ve İngilizce öğrenme kaygısını ölçemeye dönük olarak hazırlandığı anlaşılmaktadır. Bu çalışmada ise yabancıların Türkçe öğrenme kaygılarını ölçmeye dönük güvenilir ve geçerli bir ölçeğin geliştirilmesi amaçlanmaktadır.

\section{Yöntem}

$\mathrm{Bu}$ bölümde araştırmanın deseni, katılımcıları, veri toplama araçları ve veri analizinde kullanılan betimsel ve istatistiksel teknikler hakkında bilgi verilmeye çalışılmışıtır.

\section{Araştırma Deseni}

Araştırmanın amacı doğrultusunda önce nitel, sonra nicel verilerin toplanması ve analizi hedeflendiğinden bu çalışma, karma yöntem araştırma desenlerinden keşfedici desenin ilkelerine uygun olarak gerçekleştirilmiş̧tir.

Karma yöntem, araştırmaya konu olan problemleri derinlemesine anlayabilmek ve cevap üretebilmek için hem nitel hem de nicel veri toplama ve analizi süreçlerini bütünleştirmeyi amaçlayan bir metottur. Bu metodun temel varsayımı, problemin çözümüne dönük farklı yaklaşımlardan yararlanılarak sorunlara anlamlı ve kalıcı çözümler sunmaktır. $\mathrm{Bu}$ süreçte hem veri toplamada hem de çözümlemede çeşitlemeler yapılarak elde edilen verilerin tutarlılıkları ve birbirlerini doğrulama durumları hakkında önemli bilgiler elde edilir.

$\mathrm{Bu}$ araştırmada öncelikle nitel veriler toplanarak nicel verilerin altyapısı oluşturulmaya çalışılmıştır. Araştırma, alanyazın taraması, doküman incelemesi, madde havuzunun hazırlanması, uzman görüşlerine başvuru (görünüş/yüzey geçerliliği) ve kapsam geçerliğini sağlama süreçleriyle başlamış; daha sonra taslak ölçekle nicel veriler elde edilmiştir. Süreçte önce nitel veriler toplandığı için bu 
verilerin analizleri yapılmış, sonra nicel veriler toplanarak çözümlenmiş, elde edilen bu iki veri tipi sentezlenerek nihai ölçeğe ulaşılmıştır (Creswell, 2014; Johnson ve Christensen, 2014). Ölçek geliştirme sürecinde sıralanan bu aşamalar karma yöntem araştırma desenlerinden keşfedici desene uygun olarak gerçekleştirilmiştir.

Yabancıların Türkçe Öğrenme Kaygıları Ölçeği’nin geliştirilmesi sürecinin işlem basamakları Şekil 1'de gösterilmiştir:

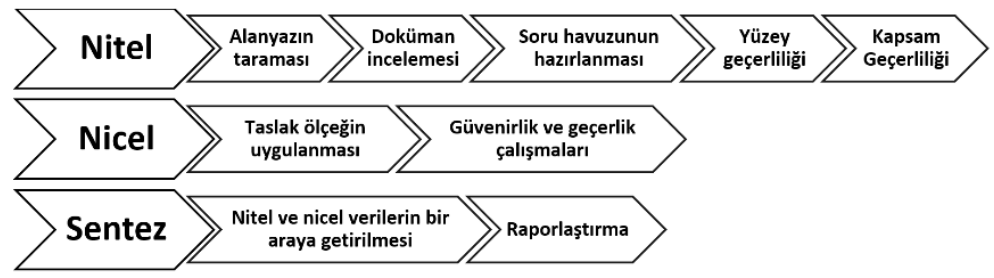

Şekil 1. Ölçek Geliştirme Süreci İşlem Basamakları

Araştırma sürecine ait detaylı bilgi katılımcılar, verilerin toplanması, analizi ve işlem başlıklarında verilmeye çalışılmıştır.

\section{Katılımcılar}

Araştırma modeline ve işlem basamaklarına bağlı olarak çalışmada hem nitel hem de nicel işlemler olduğu katılımcılar her bir süreç için ayrı ayrı açıklanmıştır.

Araştırmanın nitel kısmında taslak ölçek için hazırlanan madde havuzundaki maddelerin yüzey geçerliğini, taslak ölçeğin kapsam geçerliğini ve yabanc1 öğrencilerle yapılması planlanan odak grup görüşmesi için uzman ve öğrencilerden destek alınmıştır. Madde havuzunun yüzey geçerliğini yapmak için ölçek geliştirme konusunda uzman 4 akademisyenin görüşleri alınmıştır. Taslak ölçeğin kapsam geçerliğini sağlamak için ise 10 uzmandan destek alınmıştır. Odak grup görüşmesinde ise madde havuzunda yer alabilecek soruların tespit edilebilmesi amacıyla en az A2 düzeyinde olan 8 yabancı uyruklu öğrenciyle odak grup görüşmesi yapılmıştır.

Araştırmanın nicel kısmında ise pilot uygulamada Atatürk Üniversitesinin farklı bölümlerinde öğrenim gören 30 yabancı uyruklu öğrenci; asıl uygulamada ise 20182019 öğretim yılında Nişantaşı Üniversitesi Türkçe Hazırlık Sınıfı, Atatürk Üniversitesi Türkçe Öğretim Merkezi (TÖMER) ve Harran Üniversitesi TÖMER'de öğrenim gören en az A2 düzeyinde Türkçe bilen 325 yabancı uyruklu öğrenci yer almıştır.

Çalışma grubu ile ilgili bilgiler Tablo 1'de gösterilmiştir: 
Tablo 1.

Deneysel Uygulamaya Katılan Öğrencilerin Özellikleri

\begin{tabular}{|c|c|c|c|c|c|c|c|c|}
\hline & \multicolumn{2}{|c|}{ Cinsiyet } & \multicolumn{6}{|c|}{ Dil Düzeyi } \\
\hline & $\mathrm{E}$ & $\mathrm{K}$ & A1 & $\mathrm{A} 2$ & B1 & B2 & $\mathrm{C} 1$ & $\mathrm{C} 2$ \\
\hline $\begin{array}{l}\text { Nişantaşı Üniversitesi } \\
\text { Türkçe Hazırlık Sınıfı }\end{array}$ & 55 & 25 & - & 8 & 26 & 34 & 12 & - \\
\hline $\begin{array}{l}\text { Atatürk Üniversitesi } \\
\text { TÖMER }\end{array}$ & 50 & 32 & - & 6 & 27 & 33 & 16 & - \\
\hline $\begin{array}{l}\text { Harran Üniversitesi } \\
\text { TÖMER }\end{array}$ & 97 & 73 & - & 37 & 54 & 65 & 14 & - \\
\hline
\end{tabular}

Çalışmada, hem nitel hem de nicel araştırma süreçlerinde toplam 377 katılımcı yer almıştır.

\section{Veri Toplama Aracı}

Araştırmada veri toplama aracı olarak yabancıların Türkçe öğrenme kaygılarını ölçmeye yönelik hazırlanan ölçek kullanılmıştır. Başlangıçta 33 maddeden oluşan taslak ölçek, 5'li likert tipi bir ölçektir. Ölçek kullanılırken 5-Tamamen katılıyorum, 4-Büyük ölçüde katıllyorum, 3-Kararsızım, 2-Çok az katıllyorum, 1-Hiç katılmıyorum şeklinde cevaplandırılmıştır.

\section{Verilerin Analizi}

Taslak ölçek uygulandıktan sonra veri analizine geçilmeden önce katılımcıların ölçeği, ölçekte belirtilen yönergeye uygun olarak cevaplayıp cevaplamadıkları kontrol edilmiştir. Öğrencilerden dönen 325 ölçeğin yönergeye uygun olarak cevaplandığı tespit edilmiştir. Uygulamadan elde edilen veriler SPSS 22 programına aktarılarak işlenmiştir.

Yabancıların Türkçe Öğrenme Kaygıları Ölçeği’nin madde ayırt edicilik hesaplamaları, alt ve üst grupların ortalamalarının t testi ile karşılaştırılması ile yapılmıştır. Ölçeğin yapı geçerliğine, Açımlayıcı Faktör Analizi (AFA) tekniğiyle bakılmıştır. Bu tekniğin kullanılabilmesi için veri setinin AFA'ya uygun olması gerekir. Veri setinin uygunluğuna bakmak için küresellik testlerinden KMO testi yapılmıştır. AFA'da minimum faktör yükü olarak 0,32 olarak belirlenmiştir. Bu değerin altındaki maddeler taslak ölçekten çıkarılmıştır. Güvenirlik hesaplamalarında ise Cronbach Alpha katsayısına bakılmıştır. AFA'da ulaşılan boyutların teyit edilmesi için de Doğrulayıcı Faktör Analizi (AFA) uygulanmıştır.

\section{İşlem}

Yabancıların Türkçe Öğrenme Kaygıları Ölçeği’nin geliştirilmesi sürecinde izlenen bilimsel işlem basamakları şu şekilde sıralanabilir: 
Ölçekte yer almaya aday maddelerin tespit edilebilmesi amacıyla öncelikle öğrenmede kaygı etkeni, yabancı dil kaygısı, dil öğretiminde kaygı, okuma kaygısı, yazma kaygısı, konuşma kaygısı, dinleme kaygısı anahtar kavramlarından hareketle ilgili alanyazın taraması yapılmıştır. Ulaşılan çalışmalarda özellikle ölçek maddelerindeki kaygı ifadelerinin nasıl yansıtıldığına bakılmıştır. Daha sonra Türkçeyi yabancı dil olarak öğrenen 8 öğrenciyle yaklaşık bir saat süren bir odak grup görüşmesi yapılmış, görüşmede öğrencilerin Türkçe öğrenirken yaşadıkları korku, endişe, heyecan, tedirginlik ve kaygı faktörleri üzerinde durularak madde yazımına dönük notlar alınmıştır. Yabancı dil öğrenme kaygısıyla ilgili yazılan araştırma raporları, derlemeler ve öğrencilerle yapılan odak grup görüşmesinden hareketle 51 sorudan oluşan bir madde havuzu oluşturulmuştur.

Madde havuzunun yüzey geçerliğini sağlamak için alanında uzman 4 akademisyenin görüşlerine başvurulmuştur. Yüzey geçerliğinin yapılmasındaki temel gaye, havuzda yer alan maddelerin öğrenciler için uygunluk durumunu tespit edebilmektir (DeVellis, 2003: 57). Madde havuzundaki sorular uzmanlar tarafindan imla, dil, anlatım, soruların ifade ediliş şekilleri ve anlaşılabilirlik açısından değerlendirilmiş, hatalı sorular düzeltilmiş, amaca hizmet etmediği gerekçesiyle 15, tekrar niteliğinde soru olduğu içinse 3 soru madde havuzundan çıkarılmıştır. Geriye kalan 33 soru taslak ölçeğe alınmıştır.

Türkçeyi yabancı dil olarak öğrenenlerin Türkçe öğrenme kaygılarını ölçmedeki başarısını test etmek için taslak ölçeğin kapsam geçerliğine bakılmıştır. Taslak ölçekte yer alan maddelerin kapsam geçerliği oranlarının tespit edilebilmesi için Lawshe tekniği (1975'ten akt. Yurdagül, 2005) uygulanmıştır. Teknik uygulanırken kapsam geçerliğinin yanı sıra taslak ölçekteki maddelerin hedef kitleye uygunlukları da değerlendirilmiştir. Bu tekniğe göre en az 5, en fazla 40 uzmanın görüşüne başvurulabilir. Tekniğe göre maddelerin kapsam geçerliği oranı, ölçekteki her bir madde için uygun diyen uzman sayısının toplam uzman sayısına oranının bir eksiğiyle tespit edilir. 0 ve 0'ın altında değer alan maddeler taslak ölçekten çıkarılırken 0'ın üzerinde değer alan maddelerin kararı ise Veneziano ve Hooper (1997'den akt. Yurdagül, 2005) tarafından tablo hâline dönüştürülen asgari değerler dikkate alınarak verilir. Lawshe tekniğinde ulaşılan asgari değerler, ilgili maddenin istatistiksel olarak önem derecesini de vermektedir. Tablo 2'de kapsam geçerliği oranları için asgari değerler gösterilmiştir.

Tablo 2.

Kapsam Geçerliliği Oranları Iç̧in Asgari Dĕgerler

\begin{tabular}{llll}
\hline $\begin{array}{l}\text { Uzman } \\
\text { Sayısı }\end{array}$ & $\begin{array}{l}\text { Minimum } \\
\text { Değer }\end{array}$ & $\begin{array}{l}\text { Uzman } \\
\text { Sayısı }\end{array}$ & $\begin{array}{l}\text { Minimum } \\
\text { Değer }\end{array}$ \\
\hline 5 & 0,99 & 13 & 0,54 \\
6 & 0,99 & 14 & 0,51
\end{tabular}




\begin{tabular}{llll}
7 & 0,99 & 15 & 0,49 \\
8 & 0,78 & 20 & 0,42 \\
9 & 0,75 & 25 & 0,37 \\
10 & 0,62 & 30 & 0,33 \\
11 & 0,59 & 35 & 0,31 \\
12 & 0,56 & 40 & 0,29 \\
\hline
\end{tabular}

Taslak ölçekte yer alan maddelerin kapsam geçerliği oranlarının belirlenmesi amacıyla biri ölçme değerlendirme, ikisi psikolojik danışmanlık ve rehberlik, yedisi ise Türkçe öğretimi alanında uzman 10 akademisyenin görüşüne başvurulmuştur. Uzman görüşlerine göre taslak ölçekteki maddelerin kapsam geçerliği oranları Tablo 3'te gösterilmiştir:

Tablo 3.

Taslak Ölçekte Yer Alan Maddelerin Kapsam Geçerlik Oranları

\begin{tabular}{cccc}
\hline Madde No & $\begin{array}{c}\text { KGO } \\
\text { değeri }\end{array}$ & Madde No & $\begin{array}{c}\text { KGO } \\
\text { değeri }\end{array}$ \\
\hline 1 & 0,66 & 18 & 0,83 \\
2 & 0,83 & 19 & 0,83 \\
3 & 0,66 & 20 & 0,66 \\
4 & 0,83 & 21 & 0,83 \\
5 & 0,66 & 22 & 0,66 \\
6 & 0,66 & 23 & 0,83 \\
7 & 0,83 & 24 & 0,66 \\
8 & 0,66 & 25 & 0,66 \\
9 & 0,83 & 26 & 0,83 \\
10 & 0,83 & 27 & 0,66 \\
11 & 0,66 & 28 & 0,66 \\
12 & 0,83 & 29 & 0,83 \\
13 & 0,66 & 30 & 0,83 \\
14 & 0,83 & 31 & 0,66 \\
15 & 0,83 & 32 & 0,66 \\
16 & 0,66 & 33 & 0,66 \\
17 & 0,66 & & \\
\hline
\end{tabular}

Tablo 3'e bakıldığında taslak ölçekteki tüm maddelerin kapsam geçerliği oranlarının, asgari değer olan 0,62 'den büyük olduğu yani taslak ölçekte yer alabilecekleri anlaşılmıştır. 
Kapsam geçerliği de yapılan taslak ölçekteki 33 madde, Atatürk Üniversitesinde farklı bölümlerde öğrenim gören en az A2 düzeyindeki 30 lisans öğrencisine uygulanmış, öğrencilerin soruları anlaşılabilirlik açısından değerlendirmeleri ve anlamadıkları yerleri taslak ölçek üzerinde işaretleyerek önerilerde bulunmaları istenmiştir. Pilot uygulamadan gelen veriler doğrultusunda gerekli düzeltmeler yapılmıştır.

\section{Bulgular}

\section{Açımlayıcı Faktör Analizinden Elde Edilen Bulgular}

Ölçeğin yapı geçerliğinin incelenmesinde açımlayıcı faktör analizi (AFA) kullanılmıştır. Veri setinin AFA'ya uygun olup olmadığını anlayabilmek için Kaiser-Meyer-Olkin (KMO) ve Bartlett Sphericity testlerinden yararlanılmıştır. KMO oranının 0.60'dan büyük, Barlet tesitinden p değerinin ise 0.01'den küçük olması, veri setinin temel bileşenler analizi (AFA) için uygun olduğunu gösterir (Büyüköztürk, 2002). Taslak ölçeğin KMO ve Barlet testi değerleri Tablo 4'te gösterilmiştir:

Tablo 4. Kaiser-Meyer-Olkin Testi ve Bartlett Küresellik Testi

\begin{tabular}{llr}
\hline Kaiser-Meyer-Olkin Örneklem Yeterliliği Değeri &, 815 \\
\hline Bartlett testi & Ki-kare & 1221,352 \\
Df & 351 \\
Sig. &, 000
\end{tabular}

Tablo 4'e bakıldığında KMO değerinin 0.81, Barlet testi değerinin ise anlamlı $(\mathrm{p}<.01)$ olduğu anlaşılmaktadır. Buna göre veri setinin AFA için uygun değerleresahip olduğu söylenebilir.

Ölçülecek madde ile yapı arasındaki korelasyon, faktör yüklerini vermektedir. Yapılan analizde ortaya çıkan boyutlar ve faktör yükleri incelenmiştir. K12, K13, K16, K19, K26, K31 maddelerinin birden fazla boyutta yüksek yük değeri taşıdıkları ve aralarındaki farkın da 0.10'dan küçük; K2, K9, K21, K22 ve K33 maddelerine ait faktör yüklerinin ise 0.32 'den düşük olduğu tespit edilerek bu 11 madde ölçekten çıkarılarak yeniden analiz edilmiştir. Bu analiz sonucunda öz değeri 1 'in üzerinde 6 faktörün önerildiği ve bu faktörlerin toplam varyansa yaptığı katkının 57,369 olduğu anlaşılmıştır. Faktör sayısına karar verilirken dikkat edilmesi gereken diğer bir husus da analize ilişkin yamaç-birikinti grafiğidir. 


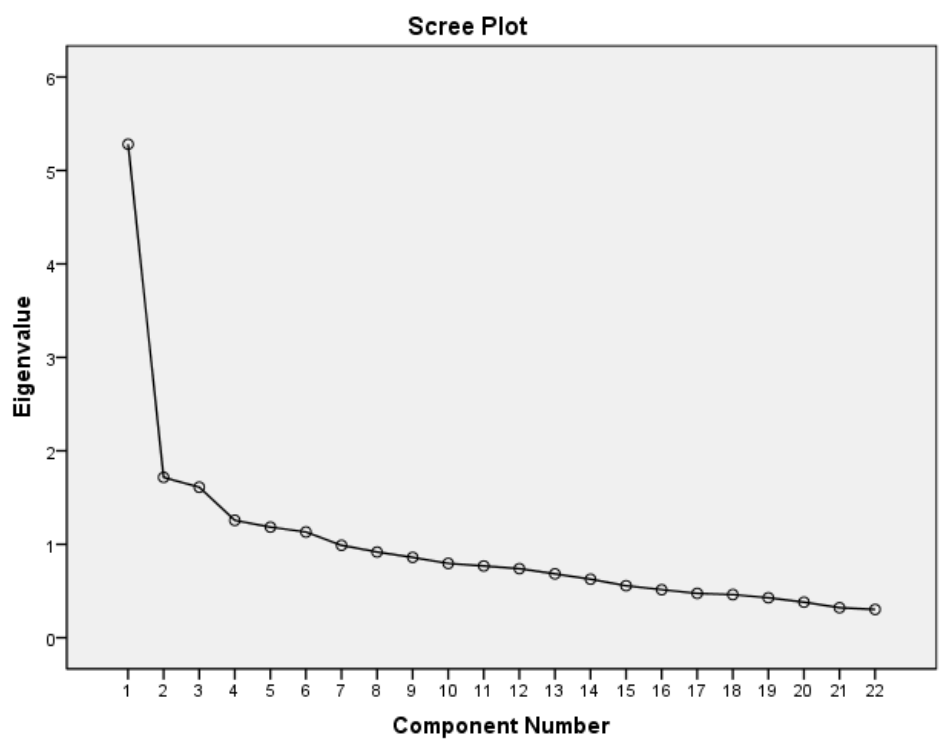

Şekil 2. Yamaç-Birikinti Grafiği

Şekil 2'ye bakıldığında üçüncü faktörden sonra grafikteki eğim bir plato yapmaktadır. Üçüncü faktörden sonraki bileşenlerin hem varyansa yaptıkları katkı azalmakta hem de birbirleriyle yaklaşı değerler almaktadır. Elde edilen bu sonuçlardan hareketle ölçeğin faktör sayısının 3 olmasına karar verilmiştir (Çokluk, Şekercioğlu ve Büyüköztürk, 2012). Faktör sayısına karar verildikten sonra yeniden bir analiz yapılmış ve faktör dağılımı Tablo 6'da gösterilmiştir.

Tablo 6.

Toplam Varyans Değerleri

\begin{tabular}{|c|c|c|c|c|c|c|}
\hline \multirow[b]{2}{*}{ : } & \multicolumn{3}{|c|}{ İlk Açıklanan Varyans Değerleri } & \multicolumn{2}{|c|}{$\begin{array}{l}\text { Döndürme Sonrasi } \\
\text { Varyans Değerleri }\end{array}$} & Açıklanan \\
\hline & $\begin{array}{c}\text { Toplam } \\
\text { Öz } \\
\text { Değer }\end{array}$ & $\begin{array}{c}\text { Varyans } \\
(\%)\end{array}$ & $\begin{array}{l}\text { Kümülatif } \\
\text { Varyans } \\
(\%)\end{array}$ & $\begin{array}{l}\text { Toplam } \\
\text { Öz } \\
\text { Değer }\end{array}$ & $\begin{array}{c}\text { Varyans } \\
(\%)\end{array}$ & $\begin{array}{c}\text { Kümülatif } \\
\text { Varyans } \\
(\%)\end{array}$ \\
\hline 1 & 5,281 & 26,006 & 26,006 & 5,281 & 26,006 & 26,006 \\
\hline 2 & 1,716 & 7,801 & 33,807 & 1,716 & 7,801 & 32,807 \\
\hline 3 & 1,611 & 7,324 & 41,131 & 1,611 & 7,324 & 41,131 \\
\hline 4 & 1,257 & 5,712 & 46,843 & & & \\
\hline 5 & 1,184 & 5,382 & 52,225 & & & \\
\hline 6 & 1,132 & 5,144 & 57,369 & & & \\
\hline
\end{tabular}


Ölçeğin 3 faktörlü olmasına karar verildikten sonra veri setine üç faktörlü bir varimax döndürme uygulanmış ve elde edilen sonuçlar Tablo 7'de gösterilmiştir.

Tablo 7.

Döndürülmüş Bileşenler Matrisi

\begin{tabular}{|c|c|c|c|}
\hline & Faktör 1 & Faktör 2 & Faktör 3 \\
\hline K14 & ,695 & & \\
\hline K29 & 613, & & \\
\hline K30 & ,602 & & \\
\hline K20 &, 580 & & \\
\hline K15 &, 504 & & \\
\hline K23 & , 479 & & \\
\hline K24 & ,478 & & \\
\hline K27 & , 447 & & \\
\hline K28 & ,428 & & \\
\hline K1 & & ,639 & \\
\hline K3 & & ,629 & \\
\hline K11 & &, 586 & \\
\hline K5 & &, 584 & \\
\hline K10 & &, 559 & \\
\hline K8 & &, 558 & \\
\hline K7 & &, 555 & \\
\hline K18 & &, 501 & \\
\hline K32 & & & ,657 \\
\hline K17 & & & ,629 \\
\hline K25 & & & ,603 \\
\hline K6 & & &, 500 \\
\hline K4 & & & ,484 \\
\hline
\end{tabular}

Tablo 7'ye bakıldığında faktör yüklerinin 0.76 ile 0.41 arasında dağılım gösterdiği ve bu değerlerin kabul düzeylerini karşıladığı anlaşılmaktadır.

\section{Doğrulayıcı Faktör Analizinden Elde Edilen Bulgular}

Taslak ölçeğe uygulanan açımlayıcı faktör analizi ile ölçeğin üç faktörlü bir yapıya sahip olduğu anlaşılmış, bunun test edilmesi için doğrulayıcı faktör analizi yapılmıştır. 


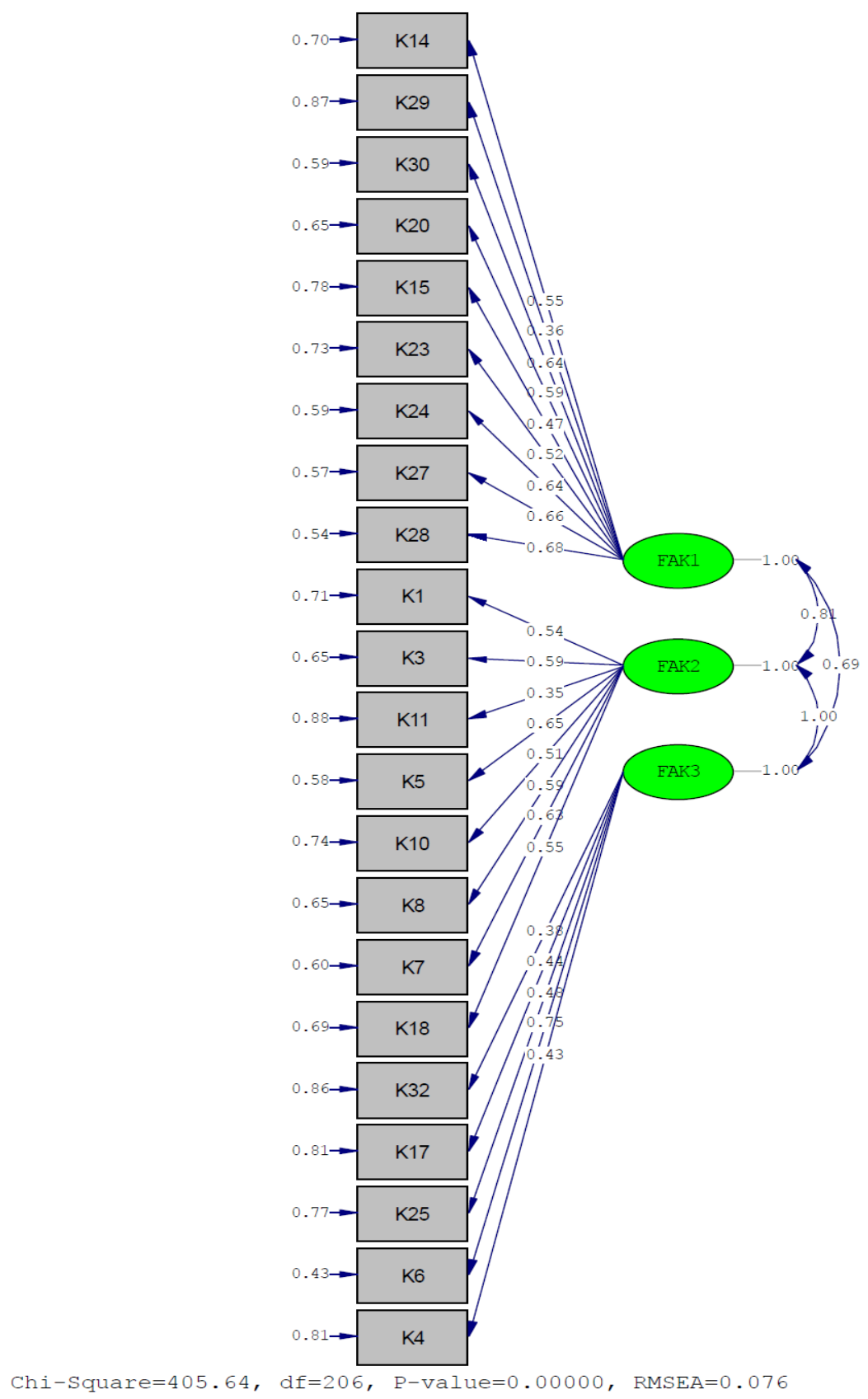

Şekil 3. AFA Örüntü Çizelgesi 
Şekil 3'te Yabancıların Türkçe Öğrenme Kaygıları Ölçeği'nin üç faktörlü modeline ilişkin path diyagramı ve faktör yükleri verilmiştir. Şekil 2'ye bakıldığında modele ilişkin faktör yüklerinin 0,35 ile 0,75 arasında değiştiği görülmektedir. Birinci faktördeki maddelerin faktör yüklerinin 0,36 ile 0,68 arasında değiștiği, ikinci faktördeki maddelerin faktör yüklerinin ise 0,35 ile 0,65 arasında değiştiği, üçüncü faktördeki maddelerin faktör yüklerinin 0,38 ile 0,75 arasında değiştiği görülmektedir.

22 maddeden oluşan taslak ölçeğe uygulanan AFA'dan elde edilen bulgular Tablo 8'de gösterilmiştir:

Tablo 8.

Taslak Ölçeğe Ait Uyum Indeksleri ve Uyum Indekslerinin Sınır Değerleri

\begin{tabular}{lccccccccccc}
\hline & $\chi 2$ & sd & $\chi 2 / d f$ & GFI & AGFI & NNFI & CFI & RMSR & SRMR & RMSEA \\
\hline MASMÖ & 403,48 & 201 & 2,004 & 0,86 & 0,81 & 0,92 & 0,93 & 0,015 & 0,068 & 0,078 \\
\hline Sinır & & & $\leq 5$ & $\geq$ & $\geq$ & $\geq$ & $\geq$ & $\leq 0,10$ & $\leq 0,10$ & $\leq 0,08$ \\
Değerler & & & & 0,85 & 0,80 & 0,80 & 0,80 & & &
\end{tabular}

GFI: goodness-of-fit index; AGFI: adjusted goodness of fit index; NNFI: non-normed fit index; CFI: comparative fit index; RMSR: root mean square residual; SRMR: standardized root mean square residual; RMSEA: root mean square error of approximation

Tablo 8'e bakıldığında kurulan modelde $\chi 2 /$ sd değerinin $(403,48 / 201=2,004)$ DFA için iyi bir uyum gösterdiği anlaşılmaktadır [SRMR=0,068, GFI=0,86, RMSEA=0,078, CFI=0,93] (Tabachnick ve Fidell, 1996). RMSEA değeri incelendiğinde 0,078 düzeyinde bir uyum indeksi elde edildiği görülmektedir. RMSEA'nın 0,08'den küçük olması uyum indeksinin iyi olduğunu göstermektedir (Hair, Anderson, Tahtam ve Black, Sümer, 2000).

\section{Güvenirlik ve Madde Ayırt Edicilik Çalışması}

Ölçeğe uygulanan AFA ve DFA testlerinden sonra ölçeğin güvenirlik çalışması için Cronbach alfa katsayısı hesaplanmıştır. Cronbach Alfa katsayısı birinci boyut için, 0 , 890; ikinci boyut için 0,873 ; üçüncü faktör için 0,823 ; dördüncü faktör için 0,867 ; ölçeğin tamamı için ise 0,90 olarak hesaplanmıştır. Bu değer ölçeğin yüksek derecede bir güvenirliğe sahip olduğunu göstermektedir (Akgül ve Çevik, 2003). Ölçek maddelerinin ayırt ediciliklerinin hesaplanması için ise ölçeğin düzeltilmiş madde toplam korelasyonlarına ve $\% 27$ alt ve üst grupların madde puanlarındaki farklara ilişkin t değerlerine bakılmıştır. 
Tablo 9.

Ölçeğin Düzeltilmiş Madde-Toplam Korelasyonlarl ve \%27'lik Alt-Üst Grup Farkına İlişkin t Değerleri

\begin{tabular}{|c|c|c|}
\hline Madde & $\begin{array}{l}\text { Madde toplam } \\
\text { korelasyonu }\end{array}$ & $\mathrm{t}$ \\
\hline 1 & 45 & 11,750 \\
\hline 2 & 50 & 18,801 \\
\hline 3 & 39 & 20,756 \\
\hline 4 & 53 & 18,490 \\
\hline 5 & 38 & 13,458 \\
\hline 6 & 37 & 19,374 \\
\hline 7 & 54 & 17,306 \\
\hline 8 & 56 & 15,632 \\
\hline 9 & 40 & 11,239 \\
\hline 10 & 43 & 16,763 \\
\hline 11 & 52 & 17,945 \\
\hline 12 & 55 & 20,564 \\
\hline 13 & 47 & 14,457 \\
\hline 14 & 45 & 15,740 \\
\hline 15 & 33 & 14,056 \\
\hline 16 & 31 & 10,980 \\
\hline 17 & 34 & 15,789 \\
\hline 18 & 55 & 16,450 \\
\hline 19 & 48 & 22,760 \\
\hline 20 & 57 & 9,753 \\
\hline 21 & 51 & 18,678 \\
\hline 22 & 39 & 12,245 \\
\hline
\end{tabular}

Tablo 9'a bakıldığında ölçeğin düzeltilmiş madde toplam korelasyonlarının 0,31 ile 0,57 arasında değiştiği, \%27'lik alt ve üst grupların madde puanlarındaki farklara ilişkin t değerlerinin ise 9,753 ile 22,760 arasında sıralandığ görülmektedir. Alt ve üst gruplar arasında anlamlı farkın bulunması ölçekteki maddelerin ayırt edici olduğu anlamına gelmektedir.

\section{Sonuç ve Tartışma}

Araştırmada Türkçeyi yabancı dil olarak öğrenenlerin Türkçe öğrenme kaygılarını ölçmek amacıyla 22 maddeden oluşan Likert tipi bir ölçek geliştirilmiştir. Ölçek geliştirme sürecinde ilk olarak belirlenen anahtar kavramlardan hareketle alanyazın 
taraması yapılmış, sonrasında Türkçeyi yabancı dil olarak öğrenen sekiz kişilik öğrenci grubuyla odak grup görüşmesi yapılarak yabancı dil öğrenmeye ilişkin kayg1 ifadeleri tespit edilmeye çalışılmış ve 51 sorudan oluşan madde havuzu oluşturulmuştur. Madde havuzunun yüzey geçerliliğini yapmak için dört akademisyenin görüşü alınarak 18 soru elenmiş ve 33 soruluk taslak ölçek elde edilmiştir. Taslak ölçeğin kapsam geçerliliğini yapmak için Lawshe Tekniği'ne başvurularak 10 akademisyenin katılımıyla maddeler test edilmiştir. Yapılan analizde taslak ölçekteki maddelerin kapsam geçerliği oranlarının kabul edilebilir düzeyde olduğu anlaşılmıştır. Kapsam geçerliği tamamlanan taslak ölçek Atatürk Üniversitesinde farklı bölümlerde öğrenim gören 30 kişilik bir öğrenci grubuna uygulanarak öğrencilerden maddelerin anlaşılabilirliğine dönük geri bildirimler alınarak gerekli düzeltmeler yapılmıştır. Pilot uygulama da yapıldıktan sonra 33 soruluk taslak ölçek en az A2 düzeyinde Türkçe konuşan 325 kişilik gruba uygulanmıştır.

Taslak ölçeğe faktör analizi uygulamak için öncelikle veri setinin AFA'ya uygunluğunu belirlemek için Kaiser-Meyer-Olkin Testi ve Bartlett Küresellik Testi yapılmış, veri setinin temel bileşenler testi için uygun olduğu anlaşılmıştır $(\mathrm{p}<.01)$. AFA analizinde maddelerin faktör yükleri incelenmiş, altı maddenin (K12, K13, K16, K19, K26, K31) birden fazla boyutta yüksek değer aldığı ve aralarındaki farkın ise 0.10 'dan küçük; $\mathrm{K} 2$, K9, K21, K22 ve K33 maddelerine ait faktör yüklerinin ise 0.32 'den düşük olduğu görülerek bu maddeler taslak ölçekten çıkarılmıştır. Yapılan AFA ile taslak ölçeğin öz değeri 1'den büyük 6 boyutunun olduğu, fakat üçüncü faktörden sonraki boyutların toplam varyansa yaptıkları katkının azaldığı, yamaçbirikinti grafiğindeki eğimin bir plato yaptığı görülmüş ve taslak ölçeğin üç boyuttan oluştuğuna karar verilerek varimax dik döndürme için üç faktörlü yeni bir analiz yapılmıştır. Döndürme sonrası açıklanan varyansın \%41,131 olduğu anlaşılmıştır. Birinci faktörde 9, ikinci faktörde 8, üçüncü faktörde 5 madde yer almıştır.

Taslak ölçeğe AFA uygulandıktan sonra üç faktörlü yapının test edilmesi için DFA uygulanmıştır. Yapılan analizde kurulan modelin DFA için iyi bir uyum gösterdiği $(\chi 2 / \mathrm{sd}=403,48 / 201=2,004 ; \mathrm{p}=.000 ; \mathrm{RMSEA}=.078<.08)$ anlaşı1mıştır.

DFA analizi sonrasında geriye kalan 22 maddenin güvenirliği için Cronbach alfa katsayısına bakılmış ve 0,90 düzeyinde bir değere sahip olduğu görülmüştür. Maddelerin ayırt ediciliklerinin hesaplanması amacıyla $\% 27$ alt ve üst grupların madde puanlarındaki farklara ilişkin $\mathrm{t}$ değerlerine bakılmış ve tüm maddelerin ayırt edici olduğu anlaşılmıştır.

AFA, DFA, güvenirlik ve \%27'lik alt ve üst grupların madde puanlarındaki farklara ilişkin $\mathrm{t}$ değeri hesaplamaları sonrası 22 maddeden oluşan nihai forma ulaşılmıştır. K14, K29, K30, K20, K15, K23, K24, K27, K28 maddeleri birinci boyutta, K1, K3, K11, K5, K10, K8, K7, K18, maddeleri ikinci boyutta, K32, K17, K25, K6, K4 maddeleri üçüncü boyutta yer almıştır. İlgili boyutlarda kümelenen maddelerin içeriğine bakılarak birinci boyuta "ders süreci", ikinci boyuta "gündelik 
hayat", üçüncü boyuta ise "anlama-anlatma süreci isimleri verilmiştir. Nihai ölçekteki maddelerin tümü olumsuzdur. Ölçekten alınabilecek en yüksek kayg1 puanı 110, en düşük kaygı puanı ise 22'dir. Yabancıların Türkçe Öğrenme Kaygıları Ölçeği'nin nihai formu Ek 1'de verilmiştir.

\section{Kaynakça}

Akgül, A. ve Çevik, O. (2003). İstatistiksel analiz teknikleri SPSS'te işletme yönetimi uygulamaları. Ankara: Emek Ofset.

Akgün, A., Gönen, S. ve Aydın, M. (2007). İlköğretim fen ve matematik öğretmenliği öğrencilerinin kaygı düzeylerinin bazı değişkenlere göre incelenmesi. Elektronik Sosyal Bilimler Dergisi, 6(20), 283-299.

Aktaş, B. (2018). Türkçeyi yabancı dil olarak öğrenen öğrencilerin sınıf içi kaygı durumlarının değerlendirilmesi. Nevşehir Hacı Bektaş Veli Üniversitesi Sosyal Bilimler Enstitüsü, Nevşehir.

Aydın, B. (1999). Konuşma ve yazma derslerinde yabancı dil öğrenimindeki kaygı nedenleri. Yayımlanmamış doktora tezi. Anadolu Üniversitesi Sosyal Bilimler Enstitüsü, Eskişehir.

Aydın, S. ve Zengin, B. (2008). Yabancı dil öğreniminde kaygı: Bir literatür özeti. Journal of Language and Linguistic Studies, 4(1), 81-94.

Aydın, Y. (2016). Lise öğrencilerinin yabancı dil kaygısının farklı değişkenler açısından incelenmesi. Yayımlanmamış Yüksek Lisans Tezi. Ahi Evran Üniversitesi Sosyal Bilimler Enstitüsü, Kırşehir.

Batumlu, D. Z. U. (2006). YTÜ yabancı diller yüksekokulu hazırlık ögrencilerinin yabancı dil kaygılarının İngilizce başarılarına etkisi. Yayımlanmamış yüksek lisans tezi. Yıldız Teknik Üniversitesi Sosyal Bilimler Enstitüsü, İstanbul.

Batumlu, D. Z. ve Erden, M. (2007). Yıldız teknik üniversitesi yabancı diller yüksekokulu hazırlık öğrencilerinin yabancı dil kaygıları ile İngilizce başarıları arasındaki ilişki. Eğitimde Kuram ve Uygulama, 3(1),24-38.

Boylu, E. ve Çangal, Ö. (2015). Yabancı dil olarak Türkçe öğrenen Bosna-Hersekli öğrencilerin konuşma kaygılarının çeşitli değişkenler açısından incelenmesi. Uluslararası Türkçe Edebiyat Kültür Eğitim Dergisi, 4(1), 349-368.

Cheng, Y. S., Horwitz, E. K. and Shallert, D. L. (1999). Language anxiety:Differentiating writing and speaking components. Language Learning, 49, 417-446.

Creswell, J. W. (2014). Nitel, nicel ve karma yöntem yaklaşımları araştırma deseni. (Çev. Ed. S. B. Demir). Ankara: Eğiten Kitap.

Erdil, M. (2016). TÖMER' de Türkçe öğrenen yabancı öğrencilerin Türkçe öğrenmeye ilişkin kaygı düzeyleri. Yayımlanmamış yüksek lisans tezi. Çanakkale Onsekiz Mart Üniversitesi Eğitim Bilimleri Enstitüsü, Çanakkale. 
Ganschow, L. and Sparks, R. L. (1996). Anxiety about foreign language learning among high school women. The Modern Language Journal, 80, 199-212.

Genç (2009), İnönü üniversitesi yabancı diller yüksekokulu öğrencilerinin yabancı dil kaygilar1. E- journal of New World Sciences Academy, 4(3), 1080-1087.

Gülözer, A. (2010). Farklıtest formatları ile ölçülen yabancı dil başarısının; öğrencilerin tutumları, kaygı düzeyleri ve öğrenme stilleri ile ilişkisinin incelenmesi. Yayınlanmamış yüksek lisans tezi. Abant İzzet Baysal Üniversitesi Sosyal Bilimler Enstitüsü, Bolu.

Hair, J. F., Anderson, R. E., Tahtam, R. L., \& Black, C. W. (1998). Multivariate data analysis. (5th Edition). New Jersey: Prentice Hall.

Horwitz, E. K. and Young, D. J. (Eds.). (1991). Language anxiety: From theory and research to classroom implications. Englewood Cliffs, New Jersey: Prentice Hall.

Horwitz, E. K., Horwitz, M. B. and Cope, J. A. (1986). Foreign language classroom anxiety. Modern Language Journal, 70, 125-132.

İşcan, A. (2016). Yabanc1 dil olarak Türkçe öğretiminde yabanc1 dil kaygısının Türkçe öğrenenler üzerindeki etkisi (Ürdün Üniversitesi örneği). Dil ve Edebiyat Eğitimi Dergisi, $17,106-120$

Johnson, B. ve Christensen, L. (2014). Educational Research (Quantitative, Qualitative and Mixed Approaches. (4th Edition) (Çev. Ed. S. B. Demir). Ankara: Eğiten Kitap.

Karçiç, A. and Çetin, M. (2015). On the anxiety factor of speaking skill development among Bosnian learners. Turkish Studies, 10(11), 971-986

MacIntyre, P. D. and Gardner, R. C. (1994). The subtle effects of language anxiety on cognitive processing in the second language. Language Learning, 44, 283-305.

Melanlığlu, D. ve Demir, T. (2013). Türkçe öğrenen yabancılar için konuşma kaygısı ölçeğinin Türkçe formunun geçerlik ve güvenirlik çalışması. International Journal of Social Science, 6(3), 389-404.

Öner, Güzide. (2008). Ortaöğretim öğrencilerinin yabancı dil öğrenimlerini etkileyen etmenler. Yayımlanmamış doktora tezi. Gaziantep Üniversitesi Sosyal Bilimler Enstitüsü, Gaziantep.

Özdemir, E. (2013). Türkçeyi yabancı dil olarak öğrenenlerin konuşma kaygılarının kaynakları. Yayımlanmamış yüksek lisans tezi. Gazi Üniversitesi Eğitim Bilimleri Enstitüsü, Ankara.

Pan, V. L. (2014). Examining foreign language learning students' attitudes and classroom anxiety levels towards foreign language courses at faculty of education. Unpublished Master's Thesis, Mersin University, Mersin. 
Schunk, D. H. (2008). Learning theories: An educational perspective. (5th ed.). Upper Saddle River, New Jersey: Pearson Education, Inc.

Senemoğlu, N. (2004). Gelişim, öğrenme ve öğretim: Kuramdan uygulamaya. (4.bask1). Ankara: Gazi Kitabevi.

Sevim, O. (2014). Yabancı uyruklu öğrencilerin türkçe konuşma kaygılarının bazı değişkenler açısından incelenmesi. EKEV Akademi Dergisi, 18(60), 389-402.

Sümer, N. (2000). Yapısal eşitlik modelleri: Temel kavramlar ve örnek uygulamalar. Türk Psikoloji Yazıları, 3(6), 49-74

Şen, Ü. ve Boylu, E. (2015). Türkçeyi yabancı dil olarak öğrenen İranlı öğrencilerin konuşma kaygılarının değerlendirilmesi. Mustafa Kemal Üniversitesi Sosyal Bilimler Enstitüsü Dergisi, 12(30), 13-25.

Tabachnick, B. G. ve Fidell, L. S. (1996). Using multivariate statistics. New York: Harpercollins College Publishers.

Tekindal, S. (2009). Duyuşsal özelliklerin ölçülmesi için araç oluşturma. Ankara: PegemA Yayınc1lik.

Tunçel, H. (2014). Yabancı dil olarak Türkçeye yönelik kaygı ve kaygının yabancı dil başarısına etkisi. Turkish Studies, 9, 1023-1042.

Üldaş, İ. (2005). Öğretmenve öğretmen adaylarına yönelik matematik kaygı ölçeği geliştirilmesi ve matematik kaygısına ilişkin bir değerlendirme. Yayımlanmamış yüksek lisans tezi. Marmara Üniversitesi Eğitim Bilimleri Enstitüsü, İstanbul.

Ünlü, E. (2007). İlköğretim okullarındaki üçüncü, dördüncü ve beşinci sınıf öğrencilerinin matematik dersine yönelik tutum ve ilgilerinin belirlenmesi. Dumlupınar Üniversitesi Sosyal Bilimler Dergisi, 19, 129-148.

Veneziano L. ve Hooper J. (1997). A method for quantifying content validity of health-related questionnaires. American Journal of Health Behavior, 21(1), 67-70.

Yeşilyaprak, B. (Ed.). (2011). Ĕ̆itim psikolojisi: Gelişim-öğrenme-öğretim. (8. bask1). Ankara: Pegem Akademi Yayıncılık.

Yılmaz, G. (2018). Ortaokuldaki sı̆̆ınmacı öğrencilerin konuşma kaygılarının değerlendirilmesi. Yayımlanmamış yüksek lisans tezi. Sakarya Üniversitesi Eğitim Bilimleri Enstitüsü, Sakarya.

Yoğurtçu, K. ve Yoğurtçu, G. (2013). Yabancı dil olarak Türkçenin öğreniminde kaygının akademik başarıya etkisi. Adlyaman Üniversitesi Sosyal Bilimler Enstitüsü Dergisi Türkçenin Eğitimi Öğretimi Özel Sayısı, 6(11), 1308-9196.

Yurdagül, H. (2005). Ölçek geliştirme çalışmalarında kapsam geçerlik indeksinin kullanımı. 14. Eğitim Bilimleri Kongresi, Pamukkale Üniversitesi, Denizli. 


\section{Extended Abstract}

Anxiety, which is one of the natural reactions to different events and a feeling reasons of which are unknown, affects the individual's cognitive and emotional state, causes things to go good or bad. When a person starts to feel anxiety, he or she starts to feel one or more of the excitement such as feeling of failure, uneasiness, fear, and helplessness (Ünlü, 2001). Every person experiences these feelings but does not know how and why they feel them. Anxiety that occurs when something doesn't go right is an emotion that the individual does not like (Üldaş, 2005). Although anxiety is an uncomfortable feeling, the presence of a small amount in the person helps to prepare for possible dangers or negativities (Akgün, Gönen ve Aydın, 2007; Tekindal, 2009).

Individuals learn a new language in a physiological, sociological and psychological process. Anxiety is one of the biggest obstacles to the language learning process. The state of anxiety, that foreign language learners experience with the thought that they cannot share their thoughts and feelings successfully in the target language, directly affects their learning (Aktaş, 2018). Horwitz, Horwitz and Cope (1986), for the first time, stated that foreign language anxiety is a concept specific to the foreign language learning process and suggested that foreign language learning classes are high-level anxiety environments. It is seen that individuals who are very successful in expressing themselves in their mother tongue are suppressed their self-perceptions due to possible communication failures, fear, excitement, anxiety and panic situations occur and it is difficult to express themselves when it comes to learning a foreign language (Cheng, Horwitz ve Shallert, 1999; Horwitz, Horwitz ve Cope, 1986).

When examining the literature, the studies on foreign language learning anxiety in Turkey, researchers generally are focused on English learning anxiety. In these studies, the success of foreign language learners; were examined in terms of variables such as gender, age, compulsory / willing learning status, use of second language at home, mother education level, father education level (Batumlu ve Erden, 2007; Öner, 2008; Pan, 2014). In the researches, it was found that anxiety decreased success (Aydın, 2016; Batumlu and Erden, 2007; Gülözer, 2010; Öner, 2008), there is a high level of anxiety in learning a foreign language (Pan, 2014), compulsory English learners' anxiety is higher than selective learners (Genç, 2009), that there is no significant difference in the anxiety of learning a foreign language in terms of age variable (Genç, 2009) and gender variable (Genç, 2009; Öner, 2008). In a study examining foreign language anxiety in high school students (Aydin, 2016), it was found that there was a positive relationship between shyness and foreign language anxiety, between interest in foreign language and foreign language anxiety, and a negative relationship between motivation and foreign language anxiety.

Considering the literature on the overall, the studies on the anxiety of learning foreign languages in Turkey generally focused on English learning anxiety and it is 
understood that the developed scales were prepared in a form of adaptation from a foreign language to Turkish and to measure the anxiety of learning English.

The aim of this study is to develop a reliable and valid scale in order to measure the Turkish anxiety of foreigners.For this purpose, firstly qualitative and then quantitative data collection and analysis is aimed, this study was carried out in accordance with the principles of exploratory design from mixed method research designs.

Mixed method is a method which aims to integrate both qualitative and quantitative data collection and analysis processes in order to understand and produce answers in depth to the research problems. The basic assumption of this method is to provide meaningful and permanent solutions to the problems by using different approaches to the solution of the problem.In this process, both in data collection and analysis, variations are made to obtain important information about the consistency of the data obtained and the status of verifying each other.

In this research, firstly qualitative data were collected and the infrastructure of quantitative data was tried to be established.The research started with the processes of literature review, document review, preparation of the question pool, application to expert opinions (appearance / surface validity) and ensuring the content validity; then, quantitative data were obtained by draft scale.In the process, since qualitative data were collected first, these data were analyzed, then quantitative data were collected and analyzed, these two data types were synthesized and final scale was reached (Creswell, 2014; Johnson ve Christensen, 2014). These stages, which were listed in the scale development process, were carried out in accordance with the exploratory design from the mixed method research designs.

In line with the aim of the research, a draft scale consisting of 33 items was applied to 325 foreign students who know Turkish at least A2 level in Nişantaş1, Atatürk University and Harran Universities in 2018-2019 academic year.For the construct validity of the scale, explanatory factor analysis was applied and 6 items were eliminated due to overlapping factor loads. Confirmatory factor analysis was performed on the scale which was found to have a four-factor structure, and 5 items were eliminated because $t$ values were less than 1.96 and error variances were high, and the fit values of the model established in repeated analysis were found to be good. For the reliability of the scale, Cronbach's alpha coefficient was examined and the value of 0.90 was found that indicates a high degree of reliability. In order to calculate the distinctiveness of the scale items, $t$ values of $27 \%$ lower and upper groups were examined and it was determined that the scale items were distinctive.At the end of the study, reliability and validity studies were conducted and a four-factor scale consisting of 22 items was reached. 
Ek1. Yabancıların Türkçe Öğrenme Kaygıları Ölçeği

\begin{tabular}{|c|c|c|c|c|c|c|c|}
\hline 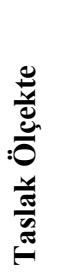 & 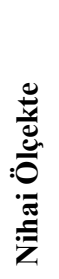 & $\begin{array}{l}\text { YABANCILARIN TÜRKÇE } \\
\text { ÖĞRENME KAYGILARI }\end{array}$ & 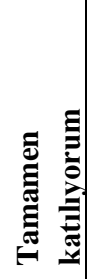 & 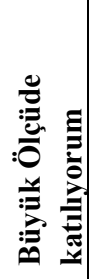 & 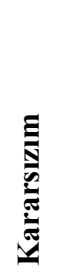 & 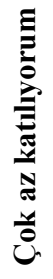 & 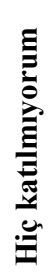 \\
\hline 14 & 1 & $\begin{array}{l}\text { Türkçe derslerinde adım söylendiğinde } \\
\text { çok heyecanlanırım. }\end{array}$ & & & & & \\
\hline 15 & 2 & $\begin{array}{l}\text { Türkçe derslerinde dikkatimi toplamakta } \\
\text { zorlanırım. }\end{array}$ & & & & & \\
\hline 20 & 3 & $\begin{array}{l}\text { Türkçe dersinin bir an önce bitmesini } \\
\text { isterim. }\end{array}$ & & & & & \\
\hline 23 & 4 & $\begin{array}{l}\text { Türkçe derslerinde genellikle huzursuz } \\
\text { olurum. }\end{array}$ & & & & & \\
\hline 24 & 5 & Türkçe derslerine katılmaktan çekinirim. & & & & & \\
\hline 27 & 6 & $\begin{array}{l}\text { Türkçe tartışma konusunda kendimi } \\
\text { yetersiz görüyorum. }\end{array}$ & & & & & \\
\hline 28 & 7 & $\begin{array}{l}\text { Türkçe dersi etkinliklerine katılmak } \\
\text { istemiyorum. }\end{array}$ & & & & & \\
\hline 29 & 8 & $\begin{array}{l}\text { Türkçe dersi sınavlarından kötü not } \\
\text { almaktan korkuyorum. }\end{array}$ & & & & & \\
\hline 30 & 9 & $\begin{array}{l}\text { Türk arkadaşlarımın konuşmamla dalga } \\
\text { geçtiğini düşünürüm. }\end{array}$ & & & & & \\
\hline 1 & 10 & $\begin{array}{l}\text { Ana dili Türkçe olanlar arasında } \\
\text { kendimi tedirgin hissederim. }\end{array}$ & & & & & \\
\hline 3 & 11 & $\begin{array}{l}\text { Düşüncelerimi Türkçe ifade etmekten } \\
\text { çekinirim. }\end{array}$ & & & & & \\
\hline 5 & 12 & Türkçe iletişim kurmaktan kaçınırım & & & & & \\
\hline 7 & 13 & Türkçe düşünürken kafam karışır. & & & & & \\
\hline 8 & 14 & $\begin{array}{l}\text { Türkçe konuşulan ortamlarda } \\
\text { durgunlaşırım. }\end{array}$ & & & & & \\
\hline 10 & 15 & Türkçe yapılan sohbetlerden çekinirim. & & & & & \\
\hline 11 & 16 & $\begin{array}{l}\text { Aniden soru sorulduğunda Türkçe } \\
\text { söyleyeceklerimi unuturum. }\end{array}$ & & & & & \\
\hline 18 & 17 & $\begin{array}{l}\text { Türkçe konuşurken hatalarımın } \\
\text { düzeltilmesinden rahatsız olurum. }\end{array}$ & & & & & \\
\hline 17 & 18 & $\begin{array}{l}\text { Türkçe söylenenleri anlamamaktan } \\
\text { korkarım. }\end{array}$ & & & & & \\
\hline 25 & 19 & Anlayamadığım Türkçe sözcükler & & & & & \\
\hline
\end{tabular}




\begin{tabular}{|c|c|l|l|l|l|l|l|}
\hline $\mathbf{3 2}$ & $\mathbf{2 0}$ & $\begin{array}{l}\text { olduğunda huzursuz olurum. } \\
\text { Karşımdaki konuşmamı anlamadığında } \\
\text { gerginleşirim. }\end{array}$ & & & & & \\
\hline $\mathbf{4}$ & $\mathbf{2 1}$ & $\begin{array}{l}\text { Türkçe konuşurken kendime } \\
\text { güvenmem. }\end{array}$ & & & & \\
\hline $\mathbf{6}$ & $\mathbf{2 2}$ & $\begin{array}{l}\text { Hazırlıksız olarak Türkçe konuşmaktan } \\
\text { endişe duyarım. }\end{array}$ & & & & \\
\hline
\end{tabular}

